\title{
Poor Quality of Treated Water in Kathmandu: Comparison with Nepal Drinking Water Quality Standards
}

\author{
Sujan Maharjan ${ }^{1}$, Tista Prasai Joshi ${ }^{1 *}$, Sujen Man Shrestha ${ }^{1}$ \\ Environment and Climate Study Laboratory, Nepal Academy of Science and Technology, Lalitpur, Nepal \\ ${ }^{*}$ Corresponding author: Dr. Tista Prasai Joshi, Nepal Academy of Science and Technology Lalitpur, \\ Nepal; E-mail: tista.prasai@nast.gov.np, tistaprasai@gmail.com
}

\begin{abstract}
Objectives: In order to evaluate the quality assurance of drinking water in Kathmandu valley, this study analyzed selected physiochemical and microbial parameters of treated water samples and compared with Nepal Drinking Water Quality Standards (NDWQS).

Methods: Treated water samples were collected from all over the Kathmandu valley and analyzed in terms of physicochemical and microbiological parameters over the period of one year from July 2017 to July 2018. The physio-chemical parameters of water samples were performed according to standard methods for the examination of water and waste water. The total coliforms were enumerated by standard membrane filtration technique.
\end{abstract}

Results: We report that microbiological aspect of treated water was the major problem as $66 \%$ of the water samples crossed the guideline value for total coliform count. Above $92 \%$ of jar water samples, $77 \%$ of tanker water samples and $69 \%$ of filtered water samples had the total coliform count exceeding the NDWQS. Moreover, $20 \%$ of bottled water was contaminated by coliform bacteria. Iron and ammonia content were found to be higher than the guideline values in $16 \%$ and $21 \%$ of the total treated water samples respectively. Analyzing the types of treated water samples showed that $35 \%$ and $15 \%$ of tanker water samples had higher ammonia and iron content respectively, and the same parameters were higher in $23 \%$ and $19 \%$ in the filtered water samples respectively than the standard criteria recommended by NDWQS.

Conclusion: The treated water samples exceed the standard values set by NDWQS and hence had poor quality. The presence of faecal pollution indicating coliform bacteria was the key problem for treated drinking water of Kathmandu valley. Therefore, monitoring and proper treatment of water should be conducted to prevent dissemination of waterborne diseases.

Key words: Ammonia, coliform, iron, treated water, water quality, NDWQS

\section{INTRODUCTION}

Water pollution is a worldwide problem and poses a serious threat to human life. For most Nepalese, obtaining sufficient water is a greater concern than obtaining safe water. Department of Water Supply and Sewerage (DWSS) reported that around $86 \%$ of the Nepalese population has access to basic water supply facility as of mid - 2015 (DWSS 2015). However, the quality of supplied water is questionable as of 2016/2017 report by Department of Health Service (DoHS) showed 23,742 cases of water borne diseases

Date of Submission: November 2, 2018

Published Online: January 2019 among inpatients in Nepal and out of which 270 cases resulted in death. The leading water borne disease was Typhoid fever causing 115 fatalities (DoHS 2016).

Those at greatest risk of waterborne disease are infants and young children, people who are debilitated and the elderly, especially when living under unsanitary conditions. So the water quality guidelines describe reasonable minimum requirements of safe practice to protect the health of consumers. No single water quality assurance approach is universally applicable, and the nature and form of drinking-water standards

Date of Acceptance: December 5, 2018

DOI: https:/ / doi.org/10.3126/tujm.v5i0.22319 
may vary among countries and regions (WHO 2017).

The drinking water quality of Kathmandu Metropolitan area has been degraded physically, chemically and microbiologically (Prasai et al. 2007). The drinking water sources of stone spouts, taps and tube wells are contaminated with total coliform. The $\mathrm{pH}$, ammonia, turbidity, electrical conductivity and arsenic level are also deviated from the WHO guidelines and Nepal standard for drinking water (Bajracharya et al. 2007). Enteric bacteria are found in biofilm in drinking water distribution system of Kathmandu valley (Shakya et al. 2012). Different treatment methods are used by most of the households in Kathmandu valley to tackle this problem. Among the various treatment methods used, boiling and using a ceramic filter are the most common ones (Shrestha et al. 2016; Shrestha et al. 2018).

Many countries with water scarcity and poor quality drinking water depend on packaged, bottled, and treated water as an alternative of public water supply systems (Dindarloo et al. 2015). Household level water treatment industry has experienced significant growth over the past several years (Chaidez and Gerba 2004). These household level treatment plants are specially designed to remove a broad range of contaminants in drinking water, including colour, odour, iron and microbial contaminants. The treatment systems used include channel through activated carbon, distillation, reverse-osmosis, ultra-filtration, membrane filters and UV disinfection. However, it is possible that contaminants occurrences can occur at the different stages of production of drinking water treatment systems (Smeti et al. 2009).

The intense increase in the drinking of bottled and packaged water has been prompted by users concern over increasing water pollution (Warburton 1993). The use of costly methods applying reverse osmosis and UV radiation are getting popular in Nepal (Lantagne and Clasen 2012). Commercially available processed jar water is extensively used by the public, however, the quality and safety of bottled jar water from human health perspective is questionable. In a research on jar water quality in Nepal reported the water was not safe for human consumption due of the presence of coliform bacteria (Budhathoki 2010). In the context of Nepal, the watersuppliersshould abideby the directives of National Drinking Water Quality Standards, for maintaining drinking water quality parameters (NDWQS 2005).
To ensure effective treatment in terms of pathogen removal at the water treatment system, a microbial risk assessment needs to be performed (George et al. 2015). For the safe drinking water, its physicochemical and microbiological parameters should meet the minimum requirements of drinking water quality standards. The main aim of the research study was to investigate the physicochemical and bacteriological parameters in the treated water from the Kathmandu valley.

\section{MATERIALS AND METHODS}

The experiments were conducted in the Environmental and climate study laboratory, Nepal Academy of Science and Technology (NAST). The water samples were examined for their physiochemical and microbiological quality in order to explore the contamination problems. The samples were quickly analyzed for physiochemical and total coliform count test on the arrival to the laboratory. If immediate analysis was not possible, it was stored at $4^{\circ} \mathrm{C}$ to avoid changes until analysis. Temperature and $\mathrm{pH}$ were analyzed by $\mathrm{pH}$ meter (EC210 Rocker Scientific Co.). Electrical conductivity was measured by Conductivity meter (HI 8633 HANNA). Turbidity was measured by nephelometer (HI 98713 ISO Turbidimeter HANNA). For the chemical parameters, hardness and chloride were analyzed by EDTA and Argentometric titration respectively. Iron was analyzed by phenanthroline spectrophotometric method (6715 UV/Vis Spectrophotometer JENWAY). Arsenic (QUANTOFIX® Arsenic 10 (Macherey-Nagel Germany)), ammonia (VISOCOLOR® alpha Ammonium (Macherey-NagelGermany)) and nitrate (VISOCOLOR® alpha Nitrate (Macherey-Nagel Germany)) were detected by colorimetric method. Total coliform counts were performed using the standard membrane filtration (MF) technique. The $100 \mathrm{~mL}$ water sample was filtered using $0.45 \mathrm{~mm}$ pore size, $47 \mathrm{~mm}$ diameter filter membrane as described by APHA (2005). Membrane filters were placed onto $\mathrm{m}$-Endo agar at $37^{\circ} \mathrm{C}$ and bacterial colonies were enumerated by colony counter after 24 hours.

\section{RESULTS}

Throughout the year 2017, 243 water samples from different sources such as filtered water, jar water, tanker water, and bottled water were analyzed for physicochemical and bacteriological parameters. Out of 243 samples, majority of samples 175 (72\%) were from Lalitpur district, followed by 55 (23\%) from Kathmandu and 13 (5\%) from Bhaktapur districts as shown in Figure 1. 


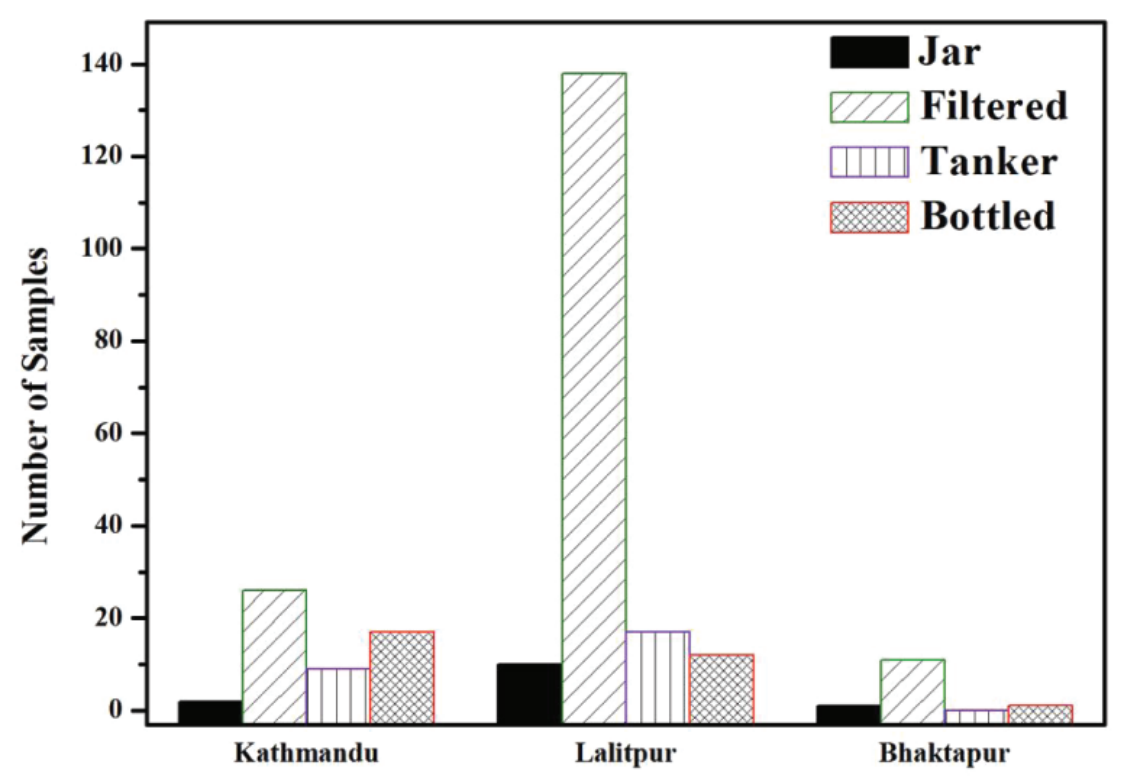

Figure 1: Treated water samples collected from Kathmandu valley

Among the treated water samples, variation of $\mathrm{pH}$, presence of ammonia and iron content were the key problem in chemical constituents. While the presence of coliform in treated drinking water was a major problem in the Kathmandu valley. Out of 243 treated sample water, $160(66 \%)$ samples contains coliform contamination. $50(21 \%), 39(16 \%), 29(12 \%), 6(2.4 \%)$ and $4(1.6 \%)$ treated water samples exceeded the national guideline value for ammonia, iron, $\mathrm{pH}$, turbidity and nitrate respectively as shown in Figure 2.

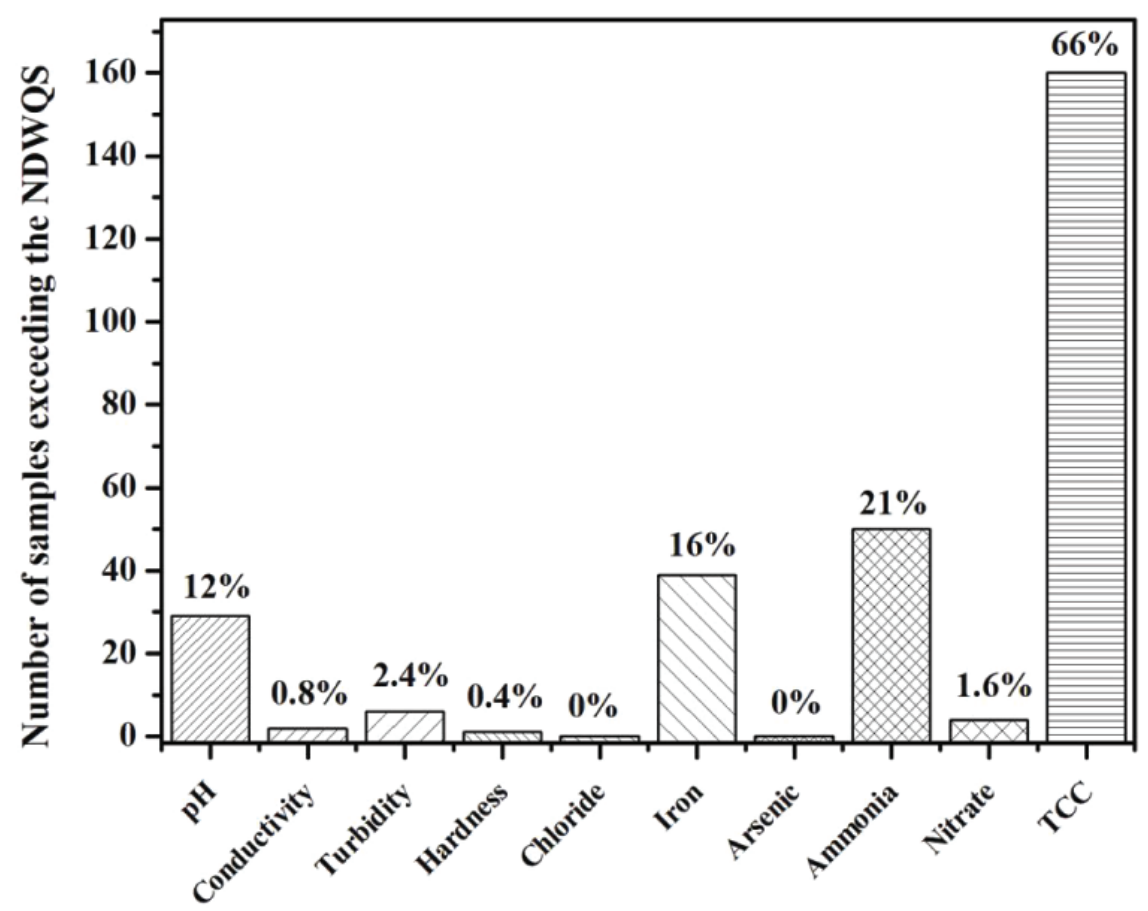

Figure 2: Frequency of treated water samples crossing the NDWQS 2005 values

The treated water was grouped as filtered water, jar water, bottled and tanker water. The tanker water is widely used for the household purpose inside the Kathmandu valley. During this study, the tanker water and filtered water had exceeded the most parameters limits of NDWQS 2005. The total number of samples exceeding the different parameters of the treated drinking water obtained from the Kathmandu valley is given in Figure 3. 


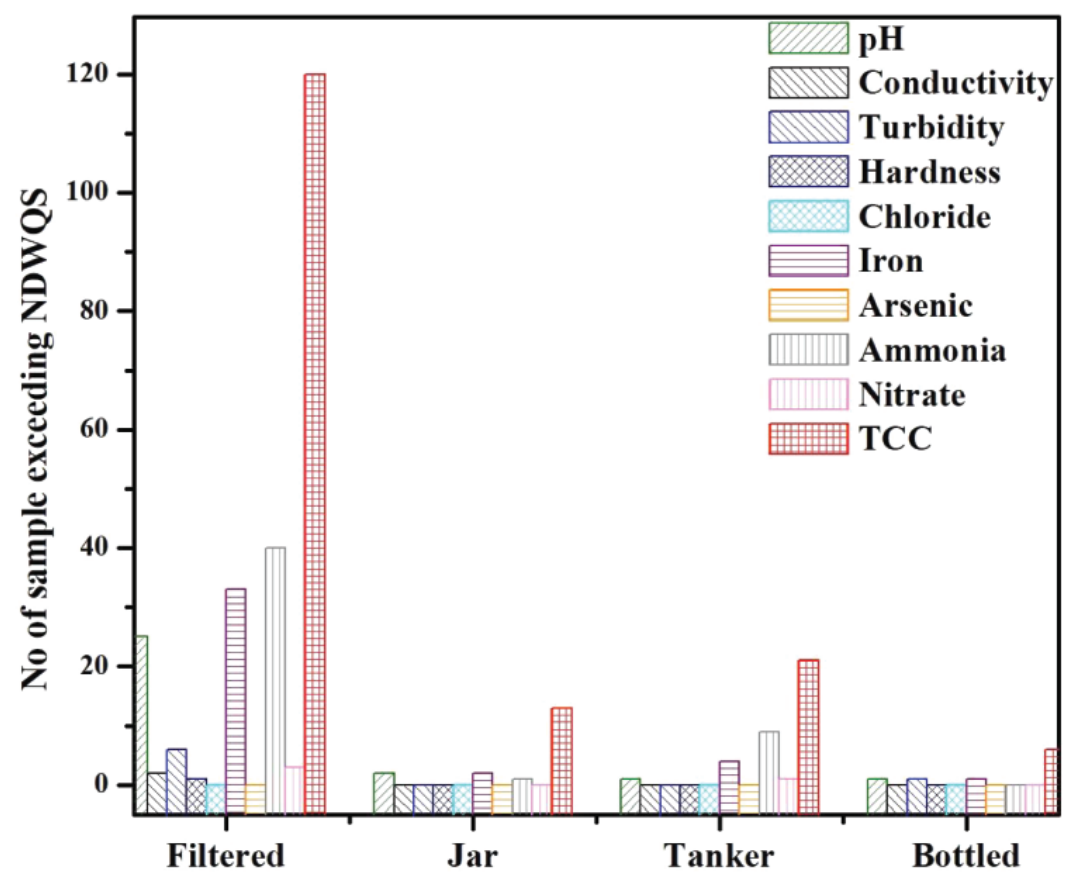

Figure 3: Frequency distribution of treated water samples crossing the NDWQS value

The study revealed that $14 \%$ of filtered water sample had $\mathrm{pH}$ value beyond the NDWQS 2005. In this study, concentration of iron $(\mathrm{Fe})$ in filtered water samples (19\%) and tanker water samples (15\%) were higher than the standard limit of NDWQS. Ammonia concentration in both filtered water samples (23\%) and tanker water samples $(35 \%)$ were higher than NDWQS limit. For microbial assessment, 69\% of filtered water samples exceeded the guideline value for total coliform count. Above $92 \%$ of jar water samples and $77 \%$ of tanker water samples exceeded the guideline value for total coliform count. While in case of bottled water, $20 \%$ of samples crossed the guideline value for total coliform count.

\section{DISCUSSION}

The main goal of this study was to evaluate the selected quality parameters of treatment claimed water available in Kathmandu valley so that the efficacy of the water treatment or post-treatment contamination could be assessed. For this we tested four types of treatment claimed drinking water samples including filtered, tanker, jar and bottled waters available in the valley. The measurements of quality parameters were judged based on National drinking water quality standards of Nepal.

The $\mathrm{pH}$ value for filtered water samples was beyond the standard limit at the time of analysis. Although $\mathrm{pH}$ is not directly related to health risk it is very important in disinfection process applying chlorine. When the $\mathrm{pH}$ exceeds 8 , disinfection is less effective while low
$\mathrm{pH}$ is acidic and is corrosive to pipes (WHO 2017). Some filtered water samples had turbidity higher than NDWQS value which questions the efficiency of filters used in removing the turbidity. Two of the filtered water samples had higher conductivity than the standard limit. Electrical conductivity is a measure of total ion content of water. The presence of salts and contaminants with waste waters increase the conductivity of the water. All the treated water samples had their hardness and chloride within the standard at the time of analysis except one filtered water sample which exceeded the hardness limit of $500 \mathrm{mg} / \mathrm{L}$. Hardness in water is caused by a variety of dissolved polyvalent metallic ions, predominantly calcium and magnesium cations. Hardness is the traditional measure of the capacity of water to react with soap, hard water requiring considerably more soap to produce a lather. Bottled and packaged waters might be naturally mineralized or naturally soft or demineralized. Thus, the mineral consumption from drinking-water and cooking water may vary widely, depending upon location, treatment and water source (WHO 2017). In this study, filtered and tanker water samples had iron content higher than the NDWQS value. Iron contamination can occur due to the excessive corrosion of iron pipes mainly due to the oxidation by dissolved oxygen to form a precipitate of iron (III) (Shrestha and Lama 2014). Usually high iron concentrations may not constitute a direct health risk but this could have a bad impact on odor and taste (Smedley et al. 1995). 
The results are found to be consistent with the various other studies conducted, which found $48 \%$ in Bhaktapur municipality, 26\% in Madhyapur Thimi and $15 \%$ of treated water samples from Kathmandu valley were contaminated with iron (Diwakar et al. 2008; Jayana et al. 2009; Koju et al. 2014). All the tested treated water samples were free from arsenic contamination. In this study, filtered and tanker water samples showed the presence of ammonia higher than the NDWQS value. Ammonia originates mainly from the metabolic, agricultural and industrial processes and can be an indicator of the possible bacterial, sewage and animal waste pollution (Shrestha and Lama 2014). Similar studies conducted on treated water samples and untreated drinking water samples from variety of sources showed that $9 \%$ and $5.17 \%$, respectively of the water samples exceeded the ammonia guideline limit (Koju et al. 2014; Diwakar et al. 2008). Previous study has reported $11 \%$ of the total drinking water samples of Madhyapur, Thimi area crossed the guideline value for ammonia (Jayana et al. 2009). Nitrate was also observed in filtered (three) and tanker (one) water samples beyond the guideline value. However, nitrate content was observed to be within the permissible level (Jayana et al. 2009; Koju et al. 2014). Nitrate contamination may cause large scale health effects through drinking-water exposure. Nitrate contamination of water might be due to the sewage and agricultural runoff. It is difficult to remove nitrate and disinfection may convert it to more toxic form. Moreover, there is a risk factor for methaemoglobinaemia caused by excess nitrate/nitrite exposure to infants of 3-6 months of age (WHO 2017).

According to WHO guidelines (2017) and NDWQS (2005), the number of total coliforms should not be observed in $100 \mathrm{~mL}$ of drinking water. In this study, most of the treated water samples showed coliform contamination which makes it unsafe for drinking purpose. Our analysis of jar water marketed in Kathmandu valley revealed that $92 \%$ of jar water samples were heavily contaminated with coliform bacteria and unsatisfactory for drinking purpose. In tanker water samples, $77 \%$ of samples crossed the guideline value for total coliform count. While in case of bottled water or processed drinking water sample available in the market, $20 \%$ of sample crossed the guideline value for total coliform count.

Previous studies reported $36 \%$ of treated water samples contained coliform bacteria indicating possible contamination of faecal origin (Koju et al. 2014). While in another study conducted in Dharan municipality Nepal, all the tap water samples and most of the bottled drinking water samples were found to be contaminated with one or more than one type of indicator organisms (Pant et al. 2016). The presence of total coliform was $26.32 \%$ in drinking jar water in Bangladesh which indicated that some of the drinking jar water samples were of poor quality which may increase the risk of water-borne diseases (Mina et al. 2018). It has been speculated that the occurrence of coliform bacteria in treated water samples implies that the treatment capacities is insufficient for the water samples. Contamination by microbial pathogens is the most direct risk, and specific regulations for private drinking water suppliers should be strictly regulated. Thus, contamination of drinking water is a major public health problem in a developing country like Nepal. Hence, there is a need for a thorough assessment of relevant physiochemical and microbiological parameters along the entire chain from the drinking water treatment.

\section{CONCLUSION}

This study revealed considerable microbial contamination of the jar water, filtered water, tanker water and bottled water. Furthermore, ammonia concentration was highest in tanker water followed by filtered water and jar water. Bottled water was safer than any other treated water used for drinking purposes with some risk of coliform contamination. Our outcomes make significant contribution to the understanding of the interconnection of water pollution and its direct effect for public health. Therefore, treated water may not always be of good quality as is perceived. For this reason, it is recommended that water for human consumption is appropriately treated for bacterial contamination before consumption. The results of these analyses indicated the need to identify the critical control points along the production stages to minimize the possible risk.

\section{ACKNOWLEDGEMENTS}

The authors are grateful to Nepal Academy of Science and Technology for providing the laboratory facilities. Thanks to all people who brought water samples at NAST research laboratory. We would like to appreciate all the help and efforts provided by the Environment Lab members especially Mr. Sujit Dahal and Ms. Smrita Acharya for their help and support.

\section{CONFLICT OF INTEREST}

The authors declare no conflict of interest.

\section{REFERENCES}

APHA (2005). Standards methods for the examination of water and waste water 21th Edition. American Public Health Association, American Water Works Association, Water Pollution Control Federation. Published by the American Public 
Health Association, Washington DC.USA

Bajracharya A, Yami K, Prasai T, Basnyat S and Lekhak B (2007). Assessment of drinking water quality of Kathmandu metropolitan areas. NJST 8: 113-118.

Budhathoki R (2010). Analysis of the physico-chemical and bacteriological parameters of bottled water available in Kathmandu valley. Dissertation submitted to Tribhuvan University.

Chaidez C and Gerba G P (2004). Comparison of the microbiologic quality of point of-use (POU)treated water and tap water. Int J Env Health Res 14(4), $253-260$

Dindarloo K, Ghaffari HR, Kheradpisheh Z, Alipour V, Ghanbarnejad A, Fakhri A and Goodarzi B (2015). Drinking water quality: comparative study of tap water, drinking bottled water and point of use (PoU) treated water in Bandar-e-Abbas, Ira. Desalin Water Treat 57 1-7.

Diwakar J, Yami KD and Prasai T (2008). Assessment of drinking water of Bhaktapur municipality area in pre-monsoon season. Sci World 6: 94.

DoHS (2016). Annual report of department of health services. Ministry of Health and Population, 23.

DWSS (2015). Annual progress review. Department of Water Supply and Sewerage, Kathmandu.

George J, An W, Joshi D, Zhang D, Yang M and Suriyanarayanan S (2015). Quantitative microbial risk assessment to estimate the health risk in urban drinking water systems of Mysore, Karnataka, India. Water Qual Expo Health 7: 331-338.

Jayana BL, Prasai T, Singh A and Yami KD (2009). Assessment of drinking water quality of madhyapur-thimi and study of antibiotic sensitivity against bacterial isolates. NJST 10: 167172.

Koju NK, Prasai T, Shrestha SM and Raut P (2014). Drinking water quality of Kathmandu valley. NJST 15: 115-120.

Lantagne DS and Clasen TF (2012). Use of household water treatment and safe storage methods in acute emergency response: case study results from Nepal, Indonesia, Kenya, and Haiti. Env Sci Tech 46: 11352-11360.

Mina SA, Marzan LW, Sultana T and Akter Y (2018). Quality assessment of commercially supplied drinking jar water in Chittagong city, Bangladesh.
Applied Water Sci 8:24.

National Drinking Quality Standards and Directives (NDWQS) (2005). Implementation directives for national drinking water quality standards. Government of Nepal, Ministry of Physical planning and Works, Kathmandu.

Pant ND, Poudyal N and Bhattacharya SK (2016). Bacteriological quality of drinking water sources and reservoirs supplying Dharan municipality of Nepal. Annals Clinical Chem Lab Med 2: 19-23.

Prasai T, Lekhak B, Joshi DR and Baral MP (2007). Microbiological analysis of drinking water of Kathmandu valley. Sci World 5: 112-114.

Shakya P, Joshi TP, Joshi DR and Bhatta DR (2012). Evaluation of physicochemicalandmicrobiological parameters of drinking water supplied from distribution systems of Kathmandu municipality. NJST 13: 179-184.

Shrestha KB, Thapa BR, Aihara Y, Shrestha S, Bhattarai AP, Bista N, Kazama F and Shindo J (2018). Hidden cost of drinking water treatment and its relation with socioeconomic status in Nepalese urban context. Water 10: 607.

Shrestha S, Aihara Y, Kondo N, Rajbhandari S, Bhattarai A, Bista N, Kazama F, Nishida K, Timilsina HP and Shindo J (2016). Household water use in the Kathmandu valley: a dry season survey. Interdisciplinary Center for River Basin Environment (ICRE), Kofu Yamanashi, Japan.

Smedley P, Edmunds W, West J, Gardner S and Pelig-Ba K (1995) Health problems related to groundwater in the Obuasi and Bolgatanga areas, Ghana. British Geological Survey Technical Report WC/95/43, Natural Environment Research Council Polaris House, North Star Avenue Swindon, 122.

Smeti EM, Thanasoulias NC, Lytras ES, Tzoumerkas PC and Golfinopoulos SK (2009). Treated water quality assurance and description of distribution networks by multivariate chemometrics. Water Res 43: 4676-4684.

Warburton DW (1993). A review of the microbiological quality of bottled water sold in Canada. Part 2. The need for more stringent standards and regulations. Can J Microbiol 39: 158-168.

World Health Organization (2017). Guidelines for drinking-water quality: first addendum to the fourth edition. Licence: CC BY-NC-SA 3.0 IGO. 